Revista Cadernos de Economia

Universidade Comunitária da Região de Chapecó - Unochapecó

\title{
MERCADO DE TRABALHO: OS DILEMAS ENFRENTADOS PELOS JOVENS GESTORES
}

\section{LABOR MARKET: THE DILEMMS FACED BY YOUNG MANAGERS}

Submissão: 18/09/2020 / Aceito: 26/10/2020.

Gustavo Oliveira Acosta ${ }^{1}$
https://orcid.org/0000-0001-8172-6177
Francielle Molon da Silva ${ }^{2}$
https://orcid.org/0000-0001-8730-6114
Larissa Ferreira Tavares
https://orcid.org/0000-0002-4962-9833

\section{Resumo}

Este estudo objetiva investigar os dilemas pessoais e profissionais enfrentados pelos jovens gestores frente a sua equipe de subordinado(s). Nessa pesquisa qualitativa descritiva os 5 (cinco) sujeitos selecionados são jovens, entre 20 e 30 anos, de ambos os sexos e sem restrição de formação profissional que exercem cargos de liderança em empresas privadas e apresentam no mínimo 1 (um) subordinado no trabalho. As entrevistas semiestruturadas foram tratadas através da análise de conteúdo e concluiu-se que o principal dilema enfrentado por esses jovens gestores é: responsabilidade atribuída a eles, pressão e cobrança do cargo de liderança, porém esse dilema aponta que as características dos gestores não estão intimamente ligadas ao problema que enfrentam, já que a maioria dos entrevistados destacou como principal característica a responsabilidade e o compromisso. A intimidade com seus funcionários também foi um impasse, pois o jovem dessa pesquisa não é adepto à formalidade.

Palavras-chave: Mercado de trabalho. Dilemas. Jovens gestores.

\begin{abstract}
This study investigate the personal and professional dilemmas faced by young managers in relation to their subordinate team (s). In this qualitative descriptive research, the 5 (five) selected subjects are young people, between 20 and 30 years old, both sexes and without restriction of professional training who exercise leadership positions in private companies and have at least 1 (one) subordinate at work. The semi-structured interviews were treated through content analysis and it was concluded that the main dilemma faced by these young managers is: responsibility attributed to them, pressure and demand for the leadership position, however this dilemma points out that the characteristics of the managers are not closely related. linked to the problem they face, since most of the interviewees highlighted responsibility and commitment as the main characteristic. The

1 Doutora em Recursos Humanos na Universidade Federal do Rio Grande do Sul. Professora na Faculdade de Administração e de Turismo da Universidade Federal de Pelotas. E-mail: franmolon@yahoo.com.br

2 Cursando MBA em Gestão de Pessoas na Universidade Estadual do Oeste do Paraná. E-mail: gustavo.oacosta@hotmail.com

3 Doutoranda em Administração na Universidade Federal de Santa Catarina. Professora no Instituto de Ciências Econômicas, Administrativas e Contábeis da Universidade Federal do Rio Grande. E-mail: larissaftavares@gmail.com
\end{abstract}




\section{Revista Cadernos de Economia}

Universidade Comunitária da Região de Chapecó - Unochapecó

intimacy with its employees was also an impasse, as the young man in this research is not adept at formality.

Keywords: Labor market. Dilemmas. Young managers.

\section{INTRODUÇÃO}

O mercado de trabalho está presente em grande parte das discussões realizadas na área de Administração, Economia, Sociologia e Psicologia. Ainda que existam diferentes vertentes nos debates realizados sobre o tema, é possível predizer que a globalização trouxe mudanças estruturais tanto nas organizações como nos sistemas produtivos e dessa forma, o mercado de trabalho se transformou de forma continuada alavancando um cenário de crescente competitividade dos agentes econômicos (ROCHA, 2008). Dessa forma, conforme afirma Bendassoli (2000), para conseguir uma inserção no mercado de trabalho e ainda manter-se nele, o indivíduo deve ter hoje um conjunto de características e competências constantemente atualizadas e que abarquem noções como flexibilidade, autonomia, capacidade de ação, comunicação e motivação.

Porém, ao que tudo indica, ainda que atendam tais características, os jovens são os mais diretamente afetados na busca pela inserção nesse contexto: mesmo que tenham a técnica ou as características necessárias, o jovem no Brasil sofre com o desemprego que é mais alto nessa faixa etária do que na população em geral devido à falta de experiência e busca de experimentação (ROCHA, 2008). Conforme a notícia publicada no Correio Braziliense ${ }^{4}$ em Janeiro de 2020, do total de desempregados no Brasil, 32\% são jovens e fatores como falta de experiência e alto custo dos encargos sociais dificultam a entrada desses jovens no mercado fazendo com que esse perfil seja um dos grupos mais vulneráveis no Brasil. Ainda assim, conforme o site $\mathrm{G} 1^{5}$, ao compararmos o crescimento da população de subocupados de 18 a 24 anos em relação ao total de

\footnotetext{
${ }^{4}$ Notícia Correio Braziliense intitulada “As dificuldades dos jovens no mercado de trabalho”. Disponível em:

https://www.correiobraziliense.com.br/app/noticia/opiniao/2020/01/03/internas_opiniao,818003/artigoas-dificuldades-dos-jovens-no-mercado-de-trabalho.shtml. Acesso em: 16/09/2020.

5 Notícia site G1 intitulada: "Jovens são os mais afetados pela piora do mercado de trabalho e comprometem o futuro da Previdência". Disponível em: https://g1.globo.com/economia/concursos-eemprego/noticia/2019/06/21/jovens-sao-os-mais-afetados-pela-piora-do-mercado-de-trabalho-e-comprometemfuturo-da-previdencia.ghtml. Acesso: 16/09/2020.
} 


\section{Revista Cadernos de Economia}

Universidade Comunitária da Região de Chapecó - Unochapecó

brasileiros, do ano de 2012 até o primeiro semestre desse ano, o aumento foi de $30,1 \%$ para $41,8 \%$.

Apesar dos números e dessa corrida para entrar no mercado de trabalho, conforme o Ministério do Trabalho, responsável pelos dados de 2017 do Cadastro Geral de Empregados e Desempregados (CAGED) ${ }^{6}$, ainda que as principais linhas de ocupação desses jovens estejam distribuídas em outros segmentos, o número de jovens em cargos de liderança/gestão vem crescendo nos últimos anos no Brasil e na visão de especialistas, uma das soluções encontradas pelas empresas são as contratações de jovens líderes bem avaliados internamente.

Como consequência, os debates em torno dessas características necessárias para ter sucesso nesse cenário são inúmeros quando analisamos a literatura de negócios: manuais e reportagens de capa que apresentam/debatem o que é preciso para entrar no mercado de trabalho e ainda ser um bom gestor/líder na atualidade. Tais discussões versam em torno de um comportamento ideal a ser seguido, como por exemplo, atitudes de liderança e espírito empreendedor.

Já na literatura científica o recente estudo de Moraes e Oliveira (2019) discute o tema de jovens no mercado de trabalho e através de uma revisão bibliográfica sobre inserção profissional nas bases científicas ELL, SciELO, EBSCO, PePSIC e CAPES na área de Administração, os autores indicam que as publicações em torno do tema problematizam a crise do mercado de trabalho e educação, a juventude sob o olhar das desigualdades sociais e econômicas e também das políticas públicas, as identidades, expectativas e experiências profissionais. A ideia aqui é relacionar o tema juventude/jovem e liderança, na área de Administração, ainda que Amaral e Oliveira (2017), da área de Economia, tenham colocado sua atenção sobre os desafios do jovem gestor, porém discutindo especificamente a primeira gestão.

Dessa maneira, conforme tais autores, visto que esta é uma linha que carece de uma literatura específica e de resultados de estudos empíricos que debatam esses dois temas juntos dentro da área este estudo tem interesse em contribuir nesta lacuna existente e se justifica uma vez que, apesar do grande número de materiais disponíveis

\footnotetext{
${ }^{6}$ Notícia intitulada "Com a retomada do emprego, mais jovens entraram no mercado de trabalho". Disponível em: www.brasil.gov.br. Acesso em 19/10/2018.
} 


\section{Revista Cadernos de Economia}

Universidade Comunitária da Região de Chapecó - Unochapecó

sobre o tema mercado de trabalho e ainda liderança e gestão, praticamente não foram encontrados trabalhos na área de Administração que abordam o assunto na idade jovem e os dilemas que essa faixa etária enfrenta quando está na liderança.

Com isso, considerando a amplitude do tema "jovens no mercado de trabalho", o recorte desse estudo é sobre os dilemas enfrentados pelos líderes jovens (jovens gestores), tendo como problemática central a seguinte questão: Quais os dilemas enfrentados pelos jovens que ocupam posição de gestão/liderança na sua área de atuação? Tendo isso em mente, esse estudo tem como objetivo geral investigar os dilemas pessoais e profissionais enfrentados pelos jovens gestores frente a sua equipe de subordinado(s), isto é, buscaremos compreender a decorrência desses dilemas levando em consideração as características pessoais e profissionais do objeto de estudo.

Torna-se importante mencionar aqui que no Brasil não há uma definição legal de população jovem, contudo, foram consideradas jovens as pessoas com idade entre 15 (quinze) e 29 (vinte e nove) anos, idade considerada pelo o Estatuto da Juventude. Nessa fase buscamos abranger o objeto de estudo aumentando em um ano o que caracteriza o Estatuto, justamente para que houvesse uma facilidade na busca, porém sem grandes alterações no resultado. Assim, foram estudados os jovens gestores, com até 30 anos de idade, que possuem cargo de liderança e que apresentam no mínimo 1 (um) subordinado em seu ambiente de trabalho.

Dito isso, as próximas páginas contemplam uma discussão em torno do tema liderança e gestão, a metodologia do estudo, os resultados encontrados e as considerações finais do estudo, bem como as referências utilizadas.

\section{LIDERANÇA: COMPREENDENDO A DISCUSSÃO GERAL}

Para atingir o objetivo da pesquisa, nesta seção apresentam-se alguns apontamentos sobre o tema gestão e liderança. Conforme dito anteriormente, uma vez que esta pesquisa visa preencher uma lacuna nos estudos de Administração sobre o líder jovem, a discussão fica em torno do processo de liderança, ou ainda a gestão de cargos de liderança, mas não necessariamente do jovem. 


\section{Revista Cadernos de Economia}

Universidade Comunitária da Região de Chapecó - Unochapecó

Segundo Bergamini (2009), a história e o interesse pela liderança são muito antigos, inclusive quanto ao próprio homem. Para o autor, no primeiro encontro de duas pessoas notou-se que, naquele momento, decisões precisariam ser tomadas, já que, possivelmente, uma dessas pessoas foi desafiada a organizar o ambiente e delegar orientações acerca de melhores soluções para os desafios. A partir daí pode-se afirmar que a origem da liderança é formada.

Refletindo sobre o tema e natureza da liderança, questiona-se na literatura se é possível desenvolver liderança ou se os traços e características já nascem com a pessoa. Tal questão fica evidente na primeira metade do século $\mathrm{XX}$, quando alguns líderes políticos, possuíam capacidade de liderança e que estas características eram inatas. Porém, logo após a Segunda Guerra Mundial, a idolatria a alguns desses líderes foi se extinguindo, devido a diversas fraquezas e desastrosas estratégias políticas e a partir daí, passou a serem observadas acentuadamente evidências de que "os verdadeiros líderes não nascem prontos, mas são formados pelas suas experiências de vida" (OLIVEIRA, 2010, p. 171).

Para o autor, sendo esta uma questão ainda não resolvida, a teoria mais aceita nos dias de hoje é que muitas pessoas já nascem com algumas características pessoais e essas podem servir para auxílio para o seu desenvolvimento nesta área, entretanto, a maior parte de sua capacidade de liderar é adquirida com as experiências ao logo da vida. Isso fica evidente no exemplo a seguir:

\footnotetext{
Um indivíduo adulto (hipotético) pode exercer liderança sobre os outros por causa de seu carisma, por se tratar de uma pessoa de excelente porte físico, ótima aparência, que fala bem e age influenciando os outros de forma cativante. É evidente que boa parte dessas qualidades nasceu com essa pessoa; mas também é verdade que, à medida que ela foi percebendo que podia fazer uso dessas qualidades naturais no seu relacionamento, aprendeu a aperfeiçoá-las (OLIVEIRA, 2010, p. 172).
}

Assim, conforme defende Chopra (2002) o importante é que o grande líder conheça a maioria das necessidades de seus seguidores, e dessa maneira, poderá atuar pontualmente nelas e assim satisfazer o que realmente importa para eles. Tal processo é indispensável e indiscutível em relação a sua importância e a qualidade dessa liderança, conforme afirmam Ulrich, Smallwood e Sweetman (2009), acontece quando o líder atende às expectativas de determinado grupo, seja ele de superiores, subordinados e até 


\section{Revista Cadernos de Economia}

Universidade Comunitária da Região de Chapecó - Unochapecó

mesmo clientes. Para os autores, o líder é eficaz quando: sabe expor, expressar seus desejos e como fazer determinada atividade/função de maneira bem clara e objetiva. Dessa forma, a equipe poderá apresentar um comportamento melhor e todos ficarão mais satisfeitos.

Além disso, os autores arriscam dizer que um líder eficaz é aquele que forma outros líderes, ajuda outros a liderar, usando como ferramenta as palavras, mas principalmente as atitudes e desenvolvendo possíveis sucessores. Corroborando essa questão Oliveira (2010, p. 170) defende que "as organizações vencedoras são aquelas capazes de produzir líderes em todos os níveis (e que) se distinguem [...] pela sua extraordinária capacidade de ensinar os outros a também serem líderes”.

De maneira mais objetiva, Newstrom (2008) define que o processo de liderança é um catalisador que transforma o potencial em realidade e afirma que "o teste final para a liderança é o grau segundo o qual ela identifica, desenvolve, canaliza e enriquece o potencial que já está presente em uma organização e em seus membros" (NEWSTROM, 2008, p.157). Além da definição do processo/atitude de liderança, os estudos sobre o tema nos remetem, conforme afirma Bergamini (2009), a liderança como uma série de trocas sociais. Para o autor, uma vez que o líder tem a intenção de promover benefícios a um determinado grupo e aos integrantes do mesmo, os membros deste grupo procuram satisfazer e honrar a sua liderança.

Assim, é possível perceber que são diversas e heterógenas as compreensões e os resultados quando refletimos sobre a atitude de liderar. A abrangência do tema é ampla e os seus limites maiores ainda, aumentando a quantidade e a diferença de definições. A respeito do conceito, o autor nos revela a seguinte expressão:

Conceituar liderança é uma tarefa até certo ponto traiçoeira e ao mesmo tempo delicada. Trata-se de conduzir uma investigação que exige o exame cuidadoso de inúmeras facetas que tem deixado perplexos até os cientistas sociais já habituados a pesquisá-la (BERGAMINI, 2009, p. 4).

Newstrom (2008), ainda afirma que a liderança é um processo de apoio e influência a outras pessoas para que elas sejam envolvidas e motivadas para a realização de suas tarefas, bem como para o atingimento dos objetivos expostos pela organização ou mesmo pelo líder, ou seja, "ela é o fator crítico que auxilia um indivíduo ou um 


\section{Revista Cadernos de Economia}

Universidade Comunitária da Região de Chapecó - Unochapecó

grupo de indivíduos a identificar suas metas, para então motivá-las e ajudá-las na conquista dessas metas" (NEWSTROM, 2008, p. 157).

Para o autor, a definição da palavra contém três importantíssimos elementos: influência/apoio, esforço voluntário e a realização de metas. Sem a presença da liderança, uma organização seria apenas um conjunto de pessoas e equipamentos agindo de maneira desordenada, da mesma maneira que uma equipe de futebol com jogadores e materiais sem seu técnico, ou ainda assim, uma orquestra com músicos e instrumentos, porém, sem maestro. Todos esses exemplos requerem uma liderança, para que o melhor dessas organizações possa ser extraído.

Nesse sentido, Lacombe (2004, p. 197) argumenta que "liderar é conduzir um grupo de pessoas, influenciando seus comportamentos e suas ações, para atingir objetivos e metas de interesse comum desse grupo [...]". Influenciar pessoas para Carvalho (2012, p. 324) é "persuadir as pessoas de tal modo que elas desejem firmemente seguir, com satisfação e entusiasmo, as orientações transmitidas de maneira que alcancem conquistas de resultados no curto, médio ou longo prazo".

Julgando demonstrar uma definição muito simples de se compreender, Oliveira (2010) sintetiza ao mostrar que a liderança ocorre quando alguém (líder) tem sucesso ao fazer com que outra(s) pessoa(s) se comporte(m) de acordo com as suas vontades, interesses e comandos. Para tanto, a liderança ocorre através de situações, ou seja, as pessoas exercem influência (lideram) sobre outras pessoas, em determinadas situações específicas, podendo não fazer o mesmo em outras situações: em cada uma das situações, poderá ser configurada uma nova circunstância que poderá ou não levar alguma pessoa a exercer a função de liderança. Para Bunn e Fumagalli (2016) o líder terá sucesso não apenas pelo que faz diariamente, mas sim, em função dos resultados de sua equipe, isto é, das vitórias e desempenhos da equipe que refletem diretamente no seu líder.

Outro ponto importante é que existem diversas formas de uma pessoa exercer influência (liderança) sobre outras, sendo elas: persuadir por meio de palavras, coagindo-as por meio de ameaças, prometendo-lhes recompensas, entre outras (OLIVEIRA, 2010). Portanto, a fonte dessa influência em que a liderança está baseada, poderá ocorrer das mais variadas formas. E por fim é que uma determinada pessoa 


\section{Revista Cadernos de Economia}

Universidade Comunitária da Região de Chapecó - Unochapecó

poderá exercer a liderança sobre outra ou ainda sobre outras pessoas ao mesmo tempo, em grupos ou não. Em ambos os casos, o processo é basicamente o mesmo. Essa definição para Oliveira (2010) também serve para identificarmos a relação entre liderança e motivação: quando o executor da atividade está motivado (expresso pelo comportamento das pessoas no cumprimento da tarefa) para realizar a atividade é sinal que a liderança é eficaz.

Após esse apanhando sobre o termo/conceito de liderança, é possível perceber que os temas liderança e gestão são conceitos muito próximos. Contudo, a liderança é uma peça fundamental na gestão e para Newstrom (2008) essa diferença poderá fazer com que líderes fortes venham a se tornar maus gerentes se houver equívoco no planejamento e fizer com que os membros de sua equipe não apontem para os objetivos, mesmo que essa permaneça operando, ainda assim possivelmente não obterá uma eficiência total na entrega de seus resultados. Por outro lado, o autor afirma que o inverso também poderá ocorrer: um líder fraco poderá ainda assim, ser eficiente em gestão, isso acontecerá especialmente, se o mesmo estiver gerenciando uma equipe que possui um conhecimento muito bom sobre as suas atividades a serem desempenhadas e ainda uma forte motivação, mesmo que externa. Contudo, essa situação é a menos provável de acontecer, por isso espera-se que bons gestores possuam uma alta capacidade de liderar, entre outras habilidades e essa capacidade poderá ser desenvolvida através de basicamente três aspectos destacados pelo autor: treinamentos específicos, a partir de aprendizado da própria experiência profissional e ainda através da observação reparadora em outros estilos de liderança, líderes eficazes.

Dessa forma, Robbins (2010) revela que apesar de existirem definições tanto para liderança quanto para a administração, elas são constantemente confundidas e que precisamos expor a liderança de maneira simples, que seja compreendida na teoria e na prática e então a define como a "capacidade de influenciar um conjunto de pessoas para alcançar metas e objetivos". A origem dessa influência poderá ser de maneira formal, onde o membro exerce um alto cargo dentro da organização, como por exemplo, um cargo de diretor. Ainda assim, conforme afirma Morais (2016), o mundo organizacional exige uma liderança e uma gestão fortes e o que se espera são esses dois aspectos 


\section{Revista Cadernos de Economia}

Universidade Comunitária da Região de Chapecó - Unochapecó

combinados que habilite o gestor a atingir os objetivos da organização, motivando funcionários e adaptando-se às mudanças.

Considerando tais definições da atividade de liderança conforme dito anteriormente em relação aos jovens no mercado de trabalho é possível pensar o quanto pode torna-se difícil essa inserção, muitas vezes pela falta de experiência de vida e profissional. Além disso, maior é a dificuldade quando refletimos sobre os cargos de gestão/liderança a serem ocupados por esses jovens. Tendo tais reflexões em mente e ainda a afirmação de Chopra (2002, p. 60) de que "não importa quão complexa e confusa possa parecer a situação, a liderança é possível em uma simples atitude: ficar à vontade na desordem", a fim de cumprir o objetivo do trabalho, a seguir apresentaremos a metodologia do trabalho para pensar os dilemas enfrentados pelos jovens gestores no mercado de trabalho.

\section{METODOLOGIA}

A fim de atingir os objetivos desse trabalho, o tipo de pesquisa selecionado foi de caráter predominantemente qualitativo. A pesquisa qualitativa é a técnica que emprega questões abertas, análises de textos e imagens, e métodos emergentes, que possibilitam uma análise subjetiva e não numérica do problema, ou seja, “a pesquisa qualitativa é exploratória e os pesquisadores a utilizam para explorar um tópico quando as variáveis e a base teórica são desconhecidas" (CRESWELL, 2007, p. 88).

Para atingir o objetivo do trabalho, a saber: investigar os dilemas pessoais e profissionais enfrentados pelos jovens gestores frente a sua equipe de subordinado(s), o instrumento de coleta de dados se deu através de entrevista semiestruturada. Marconi e Lakatos (2002) definem a entrevista como um encontro entre duas pessoas em que as informações são coletadas através de uma conversa profissional. Dessa forma, a partir das leituras realizadas e considerando as palavras de Oliveira (2010) de que os verdadeiros líderes são formados pelas suas experiências de vida e o objetivo do estudo, as questões norteadoras para a entrevista tinham a intenção de verificar o perfil do entrevistado, suas experiências profissionais, o histórico na empresa que exerce o cargo, 


\section{Revista Cadernos de Economia}

Universidade Comunitária da Região de Chapecó - Unochapecó

características de sua personalidade, vantagens e desvantagens de exercer a função de liderança e por último, a relação com os subordinados.

Em relação ao objeto de estudo, não houve restrição em relação ao sexo dos entrevistados, uma vez que há elevada importância compararmos os dilemas de ambos os sexos. A respeito da faixa etária, optou-se por fazer uma relação ao que prevê o Estatuto da Juventude, aumentando o número inicial para 20 anos, tendo em vista a dificuldade de se encontrar gestores formais abaixo dessa idade, e também aumentar para 30 anos a idade final, a fim de atingir um maior número do objeto de estudo. Quanto ao tipo de empresa, escolheu-se o setor privado, uma vez que se acreditou que no setor privado tais líderes poderiam ter mais autonomia do que no setor público.

Sendo assim, definiu-se como sujeito habilitado para a entrevista, jovens de ambos os sexos, com idade de 20 a 30 anos, que exercem cargos de liderança e que apresentam no mínimo 1 (um) subordinado em seu ambiente de trabalho, em empresas privadas, sem restrição quanto à formação profissional. Para tanto, considerando o critério de acessibilidade, foram contatadas algumas empresas na cidade de Pelotas-RS, e ao existir uma pessoa que se encaixasse nos critérios da pesquisa, foi solicitada autorização da empresa e do possível entrevistado para que fosse realizada a aplicação da pesquisa.

Dessa forma, o levantamento de dados se deu a partir de entrevista com 5 gestores que ocupavam cargo de liderança e que aceitaram participar da pesquisa. As entrevistas ocorreram no período de 08/11/2018 à 13/11/2018, em lugares distintos, sendo eles na própria empresa e na residência do entrevistado e também via internet, através do aplicativo WhatsApp. As mesmas tiveram um tempo médio de aproximadamente 15 minutos e foram conduzidas pelo autor através de questões norteadoras previamente elaboradas, havendo intervenção quando necessária. As entrevistas foram gravadas por áudio com a autorização dos entrevistados e posteriormente transcritas.

O tratamento dos dados obtidos se deu por análise de conteúdo. Esse método de pesquisa, segundo Moraes (1999), através das descrições sistemáticas, qualitativas e quantitativas, colabora na interpretação e compreensão dos dados de uma forma além da 


\section{Revista Cadernos de Economia}

Universidade Comunitária da Região de Chapecó - Unochapecó

leitura comum, sendo assim usada para descrição e interpretação do conteúdo de toda classe de textos.

Quanto ao perfil dos entrevistados, a coleta ocorreu através da acessibilidade do autor. Respeitando o perfil definido, todos eles tinham entre 20 e 30 anos e eram gestores ocupando cargos de liderança, em empresas privadas, com pelo menos 1 subordinado. Foram ao todo, entrevistados 5 gestores de empresas privadas da cidade de Pelotas/RS, de diferentes segmentos, de ambos os sexos, de idades e escolaridade diversas, com diferentes números de subordinados, conforme ilustrado na tabela 1.

Tabela 1: Perfil dos entrevistados

\begin{tabular}{ccccc}
\hline Entrevistado & Sexo & Idade & Escolaridade & Subordinados \\
EA & M & 30 & $\begin{array}{c}\text { Ens. Médio } \\
\text { Completo }\end{array}$ & 09 \\
EB & M & 28 & $\begin{array}{c}\text { Ens. Superior } \\
\text { Completo - } \\
\text { Administração }\end{array}$ & 05 \\
EC & M & 21 & $\begin{array}{c}\text { Ens. Superior } \\
\text { em Andamento - } \\
\text { Administração } \\
\text { ED }\end{array}$ \\
ME & 29 & $\begin{array}{c}\text { Ens. Médio } \\
\text { Completo } \\
\text { Ens. Superior } \\
\text { Completo }- \text { RH }\end{array}$ & 07 \\
\hline
\end{tabular}

Fonte: Dados da pesquisa, 2018. Elaborado pelo autor.

Os entrevistados tiveram suas identidades preservadas, por isso foram classificados como entrevistados A, B, C, D e E. No decorrer do trabalho, de maneira a simplificar suas nomenclaturas, serão frequentemente e respectivamente chamados de EA, EB, EC, ED e EE. Na fase de levantamento de dados, foram abordados tópicos que foram ao encontro dos objetivos determinados no estudo. Foram analisados a respeito das experiências profissionais de cada entrevistado, bem como seu histórico e tempo no cargo de liderança na atual empresa, características pessoais e/ou profissionais - 


\section{Revista Cadernos de Economia}

Universidade Comunitária da Região de Chapecó - Unochapecó

qualidades e defeitos, os benefícios e as dificuldades enfrentadas na sua gestão e ainda a relação com os subordinados.

\section{ANÁLISE DOS DADOS}

Na fase de análise e discussão dos resultados, foi elaborada uma sistematização dos tópicos abordados nas entrevistas, relatando pontos chaves de acordo com o objetivo do trabalho.

Experiências profissionais dos entrevistados

Quando falamos em liderança, muitas teorias e dúvidas aparecem, principalmente quando procuramos saber de onde vem as características de um líder, se naturais ou adquiridas no decorrer da sua vida. Para Oliveira (2010), essa é uma questão que verdadeiramente ainda não está resolvida. A teoria mais aceita, hoje em dia, é que muitas pessoas já nascem com algumas características pessoais e essas podem servir para auxílio para o seu desenvolvimento nesta área, entretanto, a maior parte de sua capacidade de liderar é adquirida com as experiências ao logo da vida.

De acordo com o objetivo de caracterizar o ingresso dos gestores no mercado de trabalho, foi solicitado aos entrevistados que comentassem um pouco sobre as suas experiências profissionais, a fim de obter um maior conhecimento dos mesmos. Com isso, percebemos que três dos cinco entrevistados começaram a ter experiências profissionais muito novos, na média dos 15 anos de idade e ainda de maneira informal, ou seja, sem carteira assinada, e os motivos foram distintos, ou seja, por necessidade ou até mesmo por opção da própria empresa contratante, conforme afirma EA: "Eu comecei a trabalhar muito cedo, com 15 anos, como autônomo, fazia o chamado bico, cortava grama, por uma questão de necessidade".

Outro aspecto analisado nesse tópico é que os EA, EB, EC, na perspectiva do autor, possuem uma experiência relevante no mercado de trabalho, inclusive em empresas e também alguns segmentos distintos, o que poderia, mas não necessariamente, trazer algum tipo de benefício na prática da liderança. Como prova 


\section{Revista Cadernos de Economia}

Universidade Comunitária da Região de Chapecó - Unochapecó

disso, podemos perceber no trecho a seguir a considerável experiência relatada pelo entrevistado que dos 28 anos de idade conta com aproximadamente 12 anos atuando em alguma atividade, seja ela formal ou não: "De vendas diretas, eu tenho 2 anos em uma distribuidora como representante comercial, aproximadamente 4 anos na empresa $\mathrm{X}$ e mais 2 na empresa $\mathrm{Y}$, totalizando 8, mais o tempo de varejo de loja que foram mais 4 anos" (EB).

Ao analisar os cargos dos entrevistados, pode-se perceber que nenhum deles começou efetivamente a exercer sua função de liderança já no início de sua trajetória no mercado de trabalho. Porém, dois deles, EB e EC, ao se formalizarem nas suas respectivas empresas, passaram então a um compromisso maior, o de liderar. EB depois de trabalhar 3 anos de maneira informal em uma empresa de pet shop na cidade de Pelotas, tem o primeiro registro na carteira de trabalho e logo com o cargo de gerente: "Eu tive por 4 anos nessa loja, 3 de maneira informal, eu não tinha carteira assinada, fiquei por mais 1 ano com a carteira assinada, que já foi com o cargo de gerente", destaca EB.

Já com EC não foi muito diferente:

"Ele (pai) já me deu a oportunidade de administrar porque eu já tinha passado vários anos trabalhando com eles (pai e tio) e acharam que eu já poderia administrar uma empresa sozinho. Então eles me deram uma loja para eu administrar."

O entrevistado menciona ainda que ganhou uma das lojas da família para administrar aos 18 anos, após ter trabalhado 4 anos de maneira informal juntamente com o pai e o tio. Outro aspecto importante a ser destacado neste tópico é a experiência em cargos de liderança anteriormente ao cargo atual em que se encontram os entrevistados. Para, Lacombe (2004, p. 197), "liderar é conduzir um grupo de pessoas, influenciando seus comportamentos e suas ações, para atingir objetivos e metas de interesse comum desse grupo".

No entanto, EC e ED afirmam nunca terem sido líderes antes e que hoje, embora já com alguns anos, exercem o papel pela primeira vez. Por outro lado, os outros três entrevistados, relatam que o papel de liderança já não é tão novo assim para eles e que em algum outro momento também se depararam com a realidade que enfrentam no seu dia a dia. Dois desses três entrevistados já tiveram mais de uma 


\section{Revista Cadernos de Economia}

Universidade Comunitária da Região de Chapecó - Unochapecó

oportunidade, anterior à atual, de desempenharem funções de autoridades: "E depois surgiu a oportunidade de eu ser líder de vendas, onde aprendi todas as atividades financeiras, ali eu aprendi a liderar equipe, a fazer a gestão de horários, faltas, férias e em seguida virei gerente da loja" (EE).

Com isso, destaca-se que as experiências profissionais e pessoais de cada um são importantes na possível construção de um líder. Porém, não há nada mais importante do que conhecer o seu liderado, tanto é que Chopra (2002) destaca que a liderança é algo secreto quanto a sua definição. Para ele, o que realmente importa e faz a diferença é que o grande líder conheça a maioria das necessidades de seus seguidores, dessa maneira, poderá atuar pontualmente nelas e assim satisfazer aquilo que realmente importa para eles.

Histórico na atual empresa

Neste tópico, também serão discutidas as experiências dos profissionais, porém agora, considerando o momento atual, dentro da própria empresa na qual exercem um cargo de liderança hoje.

A fim de identificar a trajetória profissional dos líderes, os entrevistados foram questionados acerca de seus históricos na empresa em que se encontram. De modo positivo, percebeu-se que apenas dois dos cinco entrevistados precisaram percorrer um caminho maior dentro da própria empresa para chegar ao posto que estão hoje, conforme apresentado a seguir.

EA é gerente comercial de uma rede de postos de combustível e relata ter começado como frentista, atendendo ao público e executando diversas atividades:

\footnotetext{
"Fui chamado em um posto de combustível, comecei como frentista, trabalhei por 2 anos com a pessoa que me contratou e logo após esse posto foi vendido e eu continuei com a empresa que o comprou, exercendo a mesma função, frentista.” (EA)
}

Começando pelo primeiro cargo do organograma da empresa, EA não estava satisfeito em se manter muito tempo neste cargo, então, segundo ele, procurou evoluir para subir níveis dentro da empresa e conseguiu. Após 3 anos e meio exercendo as funções de frentista ele foi promovido a chefe de pista, onde já exercia alguma espécie 


\section{Revista Cadernos de Economia}

Universidade Comunitária da Região de Chapecó - Unochapecó

de liderança e passados mais 1 ano e meio, foi promovido novamente e tornou-se gerente comercial, totalizando 5 anos para chegar ao cargo mais alto dentro de uma unidade da rede. EA hoje, chega aos 3 anos de liderança, somando 8 na mesma empresa. Além disso, esse entrevistado destaca que a experiência e seu histórico dentro da empresa contribuem para a sua gestão de equipe, principalmente de como entender o seu subordinado: "Estar do lado de lá (funcionário), ajuda bastante a saber como eles se sentem" (EA).

Para ED, a trajetória não foi muito diferente. Ele começou como caixa operador em uma rede de supermercados, exercendo operações financeiras, registro e cobrança de produtos, ficando por 1 ano e meio nessa função. Após esse período ED foi convidado a fazer parte da equipe de fiscalização da empresa, setor que cuida da parte de prevenção e perdas da loja. Após aproximadamente 4 anos e uma boa experiência no setor, de maneira provisória, o entrevistado ficou responsável pelo setor durante 8 meses, entre férias e afastamento do então líder, se destacou e foi promovido a encarregado do seu setor. Ao todo, levou aproximadamente 7 anos para se tornar líder de maneira efetiva, hoje está há 2 anos na função, totalizando 9 na mesma empresa: "Comecei em 2009 na empresa como caixa operador, durante 1 ano e meio, logo, fui convidado a ser fiscal de segurança. Depois de um tempo fiquei aproximadamente 8 meses respondendo pelo setor, me destaquei e então fui convidado a ser encarregado" (ED). O mesmo ainda destaca que a liderança sempre foi o seu objetivo. "Eu gosto de ser liderança, sempre almejei isso, desde que eu passei para o setor me esforcei ao máximo para ser líder."

Com os outros três entrevistados, a saber: EB, EC e EE, o histórico na atual empresa já ocorreu de maneira diferente. Ingressaram na empresa já exercendo a posição atual de liderança. Para EB, as experiências anteriores ajudaram a conquistar essa vaga. $\mathrm{O}$ mesmo já exercia a função de supervisor em outra empresa, quando então recebeu uma proposta da empresa atual para a mesma função. Participou de todo processo seletivo, porém só havia ele como candidato:

"Eu já era supervisor na empresa Y, então vim para Pelotas com a proposta de exercer a mesma função na empresa Z. Embora fosse um convite, participei de todos os processos da seleção, porém não tiveram mais candidatos junto". (EB). 


\section{Revista Cadernos de Economia}

Universidade Comunitária da Região de Chapecó - Unochapecó

Já para EC, os processos se deram de maneira mais simples, pelo fato de ser uma empresa familiar. Como já destacado anteriormente, aos 18 anos, depois de exercer algumas funções de maneira informal por aproximadamente 4 anos nas dependências de algumas lojas da rede da empresa de sua família, foi convidado pelo seu pai a administrar uma delas. Do mesmo modo, EE também começou na atual empresa como líder: foi contratada após uma entrevista com a gerente da franquia, depois de cadastrar seu currículo em diversos sites de emprego: "Estava sempre atualizando meu currículo, sempre colocando em sites, fiz uma entrevista com a gerente da empresa X e depois de uma semana ela me chamou para trabalhar", lembra EE.

Em relação ao tempo de liderança dos entrevistados na atual empresa, a diferença entre eles foi pequena, com no mínimo de 1 ano e no máximo 3 anos. A disposição entre eles é a seguinte: EA e EC com 3 anos cada, EB e ED com 2 anos e EE com apenas 1. Quando comparado o número de subordinados que cada um deles possui, a diferença foi consideravelmente maior: EA possui 9 subordinados, sendo todos eles do sexo masculino; EB 5, também todos do sexo masculino; EC possui 50 subordinados, sendo 45 do sexo feminino e 5 do sexo masculino; ED 7 subordinados, 5 homens e 2 mulheres e EE, 2 subordinados do sexo feminino.

Também, como resultado vale destacar que o mais novo líder em relação à idade (EC) - 18 anos, possui o maior número de subordinados - 50, nesses, contendo o maior número do sexo feminino - 45. Porém, é importante destacar que é o único que conta com funcionários em cargos de supervisão abaixo de si, ou seja, ele também lidera supervisores.

Importante destacar ainda que a única liderança do sexo feminino - EE é a que possui o menor número de subordinados: 2, e também a única a liderar apenas mulheres. Os entrevistados A e B também lideram somente pessoas do mesmo sexo, porém, homens.

Características dos entrevistados

Com o intuito de conhecer um pouco mais dos entrevistados, para saber se suas características tem relação com os dilemas enfrentados por esses jovens gestores, os 


\section{Revista Cadernos de Economia}

Universidade Comunitária da Região de Chapecó - Unochapecó

mesmos foram questionados a respeito de suas características pessoais e profissionais, expondo suas qualidades e seus defeitos.

Os meios em que os líderes usam para exercer seu poder são os mais variados e suas características irão estabelecer qual ou quais são o(s) seu(s) estilo(s). Entre muitos autores, Newstrom (2008), destaca que existem três principais estilos de liderança: autocráticos, democrático e laissez-faire ('deixa fazer', liberal), que também são encontrados com outras nomenclaturas, respectivamente, como: autoritários, consultivos e participativos.

Cada um desses estilos carrega consigo pontos positivos, mas também limitações. Porém, é muito difícil caracterizarmos fielmente um perfil, estilo de liderança, pois através das suas decisões, em diferentes ações, podem expor um misto de estilos. Segundo Newstrom (2008), geralmente o líder utiliza os três estilos durante um determinado tempo, porém um deles se destacará como sendo o dominante sobre os outros estilos.

Nessa pesquisa, destacam-se algumas qualidades dos entrevistados e peculiaridades, que sabemos que são muito importantes. Como qualidade mais apresentada, a responsabilidade aparece em três das cinco entrevistas, como característica positiva: "destacaria como responsabilidade uma das minhas qualidades" (ED). EB afirma que "uma das qualidades que eu prezo bastante é a responsabilidade" (EB) e EC complementa que "para você administrar uma empresa, acima de tudo, é você ter responsabilidade, eu sou muito responsável” (EC).

Segundo o dicionário, responsabilidade é sinônimo de dever, obrigação e sensatez, o que nos faz trazer para o mercado de trabalho, a assiduidade, pontualidade, cumprimentos das atividades que são impostas entre outras. Algumas qualidades peculiares, porém não menos importantes, também foram citadas pelos entrevistados. EA afirma que é uma pessoa muito compreensível e EB "uma pessoa bem competitiva" (EB). Tais características foram julgadas por eles como favoráveis.

Como já citado anteriormente, cada estilo de liderança possui pontos positivos e limitações. Quando questionados sobre suas limitações, ou seja, defeitos, os entrevistados foram pontuais e duas características se sobressaíram. A falta de paciência ou ser impaciente foram citadas por dois dos cinco entrevistados: "um ponto negativo é 


\section{Revista Cadernos de Economia}

Universidade Comunitária da Região de Chapecó - Unochapecó

que eu sou muito estourado, não tenho paciência" (EA). Já EE relata que "algum defeito pode ser a falta de paciência, não tenho muita paciência, eu já fui menos paciente e hoje estou aprendendo, estou em uma transição, mas não é muito fácil". O mesmo se caracteriza como uma pessoa impaciente, porém julgando que há uma necessidade de melhorar, e dessa forma tem procurado evoluir.

Também como ponto negativo em suas características, segundo os entrevistados outra questão interessante foi apresentada por dois deles, que também obtiveram a mesma visão sobre si. A expressão "não confiar no trabalho dos outros", talvez não tenha sido nem sequer pensada pelos outros três questionados, porém, foi definida como sendo um dos seus dos seus defeitos por EA e EE. Com duas maneiras distintas de exporem esse defeito por eles, o significado foi o mesmo: "às vezes tem funções que eu prefiro exercer por falta de confiança, não confio muito no serviço dos outros, então eu tenho que estar sempre revisando tudo o que os outros fazem e isso é um defeito muito grande" (EA). Ele ainda complementa: "hoje meu defeito é ser perfeccionista, é como se fosse 'você não vai conseguir fazer do jeito que eu faço'. Sei que isso é errado".

De modo prático, Pessotti (2012) relata algumas, dentre muitas outras necessidades que os líderes precisam exercer nas organizações: comunicar-se diretamente com a sua equipe, pois, ao perceber que o seu líder age de maneira comprometida e que se preocupa em delegar tarefas de maneira clara e objetiva, automaticamente a sua equipe se tornará mais confiante. Saber criticar, construindo e explorando algo de melhor no desempenho de cada um. Saber cobrar e elogiar, ser cobrado, também ensinar e aprender. Agir com ética e confiabilidade, gerando força e influenciando as pessoas.

Pessotti (2012) ainda complementa que nesse processo dentro da organização é indispensável que o líder conheça o cenário a qual a empresa está inserida. Quando o líder facilmente se comunica com o meio e com seus liderados, obtém melhores resultados. Ainda consegue o poder da empatia, o que faz toda a diferença nos relacionamentos e consequentemente nos resultados que poderão ser gerados pela equipe. 


\section{Revista Cadernos de Economia}

Universidade Comunitária da Região de Chapecó - Unochapecó

Quando observadas as necessidades que os líderes precisam exercer frente a sua equipe, destacadas pelo autor percebe-se o enquadramento de um dos entrevistados nesse perfil, não em sua totalidade, mas nas qualidades expostas e nos aspectos onde a atenção precisa ser maior. Alguns trechos da entrevista de EC, o entrevistado mais novo, de apenas 21 anos, revelam o quão assertivo ele procura ser em sua gestão: "para ser líder de uma empresa, você precisa dar exemplo, exemplo em tudo. Questões de falta, atraso, eu participo junto, eu sou muito responsável.” $O$ entrevistado ainda complementa: "Eu participo muito com o meu colaborador e acho que esse é o meu diferencial, eu procuro entender ele, entender a rotina do meu trabalho, tudo o que está acontecendo". Para ele, "um diferencial que a gente tem no nosso sucesso, é o de estar acompanhando, pois assim você consegue corrigir e aperfeiçoar muitas coisas” (EC).

Porém, o entrevistado, também considera que precisa melhorar seu desempenho em algumas áreas: "sobre defeito, acho que eu poderia aproveitar muito mais as oportunidades, aproveitar cursos, eventos relacionados a minha área, a moda, inclusive eventos locais". EC ainda afirma que o processo de participar ativamente da empresa vem de características da própria família, a qual é proprietária da rede de lojas e que fazem questão de estar sempre na empresa, participando de todos os processos, acompanhando os funcionários e estão por dentro de todos os acontecimentos.

Vantagens e dificuldades enfrentadas na liderança

Como em tudo na vida, sempre haverá uma decisão, uma ação, posição em que terão um ou mais pontos de vista, seja ele de maneira positiva ou negativa. Sempre haverá facilidades e/ou dificuldades, vantagens ou desvantagens. Isso certamente também ocorrerá em uma liderança.

O papel de um líder na organização é imprescindível, uma vez que a empresa precisa caminhar rumo aos seus objetivos estabelecidos. Dessa forma, Pessotti (2012) revela que é o líder é o responsável por essa conexão de liderados com as metas a serem alcançadas, através de treinamentos e dinamização de tarefas. Assim a organização precisa gerar meios para que haja essa ligação entre os líderes e liderados, a fim de haver incentivo para as práticas adotadas pela mesma. 


\section{Revista Cadernos de Economia}

Universidade Comunitária da Região de Chapecó - Unochapecó

O autor ainda afirma que há nas organizações necessidades de uma liderança bem preparada para os desafios que a empresa sofre ou virá a sofrer, para que consiga capacitá-la e extrair o melhor de sua equipe, tornando-a melhor a cada dia. Com o objetivo de analisar as facilidades e as vantagens de ser gestor e compreender os dilemas percebidos por eles, ou seja, suas maiores dificuldades enfrentadas na sua liderança, os entrevistados foram questionados, justamente sobre esse ponto: Quais as vantagens e dificuldades enfrentadas a exercer um cargo de liderança? E as respostas não foram tão variadas, mas muito significativas. Certamente haveria muito mais a se falar desses dois pontos de vista se acompanhássemos esses líderes no dia a dia da sua empresa, porém, relatamos alguns desses que foram lembrados por esses líderes, ou também que foram comentados como sendo um dos principais a serem destacados.

Durante a entrevista com os líderes, ficou evidente, através de comentários e até ações, que eles realmente gostam muito do que fazem e que além dos problemas, torna o seu dia a dia mais prazeroso. Assim, três dos cinco entrevistados, talvez de forma surpreendente, comentaram com um sorriso estampado no rosto que uma das principais vantagens de exercer um cargo de liderança é o fato de fazer a diferença na vida das pessoas, contribuindo para seu crescimento pessoal e profissional, ensinando, influenciando e até mesmo mudando a vida delas: "o lado positivo de você ser líder hoje é poder colaborar com o desenvolvimento das pessoas, direcionar e até mesmo ensinar. A função do líder é lapidar, extrair o melhor do seu liderado" (EB).

No mesmo sentido, o entrevistado $\mathrm{C}$ afirma que "as vantagens da liderança é tu poder sentir que faz a diferença na vida das pessoas, é tu poder administrar elas e ver a diferença. Porém, é uma função de bastante responsabilidade.” (EC). O entrevistado E completa: "O bom de ser líder é você conseguir ensinar, influenciar e também caminhar junto com o colaborador. Se você não consegue fazer isso, você não está exercendo liderança".

Seguindo, dois dos cinco entrevistados, responderam que uma das facilidades, ou seja, pontos positivos de exercer essa função hoje é justamente fazer por que gosta e que fazem com prazer. Quando questionado sobre o lado bom de ser líder, ED defende "eu gosto de ser liderança, sempre almejei isso, gosto de trabalhar com o meu pessoal, gosto muito do meu setor, gosto de fazer o que eu faço". Na mesma linha, EC afirma: 


\section{Revista Cadernos de Economia}

Universidade Comunitária da Região de Chapecó - Unochapecó

"gosto muito do que faço, eu faço por prazer, isso também é uma vantagem". Como uma resposta previsível, porém não em maioria, ainda foi citado por dois entrevistados, EA e EC, que um dos motivos que trazem algo positivo para a sua liderança, é o fato de eles possuírem autonomia. $\mathrm{Na}$ maioria das vezes, eles possuem total liberdade para tomar decisões gerenciais e administrativas, sendo muito poucas as exceções.

Como citado anteriormente, sempre há dois lados quando precisamos agir, tomar decisões e estar a frente de algo. Neste tópico, os entrevistados também comentaram um pouco das suas desvantagens e dificuldades de exercer o cargo em que exercem atualmente. O fato de ser líder em uma empresa, ser responsável por um setor ou por pessoas, certamente exigirá algo a mais dos que estão à frente, muitos deveres e responsabilidades são atribuídos a eles. E foi justamente essa questão que foi apontada por três dos cinco entrevistados, o fato de terem muitas responsabilidades, sofrerem muita pressão, serem cobrados e também precisarem cobrar, enfim, responder por praticamente tudo. Com certeza, esse é o maior dos dilemas segundo eles.

Alertando sobre a importância de saber conciliar e administrar as atividades profissionais, para que elas não influenciem diretamente na sua vida pessoal, EA argumenta que um dilema contra é o fato de ter

\footnotetext{
"muito mais responsabilidades, preocupações e é impossível não levar isso para casa, então você como gestor, acaba trabalhando 24 horas por dia, isso é muito ruim. Tem que saber conciliar, se não você acaba esquecendo a família. A gestão tem esse risco" (EA).
}

Questionado sobre o lado negativo de ser líder hoje, EB argumenta sobre lidar com "a pressão que recebe tanto da empresa quanto dos liderados, tomar decisões corretas mesmo com o bombardeio de informações e responsabilidades. É preciso ter inteligência emocional” (EB). No mesmo sentido, ED afirma que "o ruim de ser líder, é que tudo cai sobre ti, qualquer problema que dê, que apareça, tu é responsabilizado, responsabilidade de lidar, administrar o pessoal, além das minhas responsabilidades como funcionário da empresa também". Além disso, o entrevistado diz através da expressão, que "não pode estar no radar", o quanto deve cumprir com todas as obrigações para que não seja chamada a sua atenção. Ele relembra que certa vez foi advertido por uma falha de um funcionário que nem seu subordinado era. 


\section{Revista Cadernos de Economia}

Universidade Comunitária da Região de Chapecó - Unochapecó

Ainda sobre a questão da desvantagem de ser líder, em segundo lugar, com maior número de percepções, EC e EE expõem como sendo uma desvantagem a ocupação de seus cargos, o fato de não poder tratar os subordinados com muita intimidade, ter que trabalhar com muita formalidade, caso contrário, isso poderá prejudicar o seu relacionamento com os subordinados e consequentemente sua liderança:

\footnotetext{
"acho que a desvantagem em liderar, é não poder criar muita intimidade com os subordinados. Tem que separar o profissional do pessoal, é preciso trabalhar com muita formalidade. No momento em que as coisas se misturam, a liderança perde o valor, a autonomia e o respeito" (EC).
}

Para EC, único entre os cinco que possui uma escala de liderados, tem seus subordinados imediatos e esses também possuem outros subordinados. $\mathrm{O}$ entrevistado ainda lamenta muito ter que controlar esse tipo de situação e não poder participar sempre de forma ativa na vida dos funcionários, confraternizações e assim por diante, como também argumenta EE:

\footnotetext{
"uma desvantagem em exercer liderança, é a função da intimidade, por mais difícil que seja você tem que evitar e se eu pudesse dar um conselho, seria este: não seja amigo demais, por que se tu constrói uma amizade, na hora de cobrar é bem mais complicado" (EE).
}

Finalizando, também foram lembradas questões como a perda da qualidade de vida, a dificuldade com a não totalidade de autonomia e a escassez de material ou funcionário: "a liderança vai te exigir um horário maior durante o dia, durante a semana, qualquer líder terá a qualidade de vida influenciada" $\mathrm{O}$ entrevistado ainda completa "preciso estar na abertura e fechamento da empresa, intervalo, folga, férias, finais de semana sempre menores. A qualidade de vida diminui." (EC). Em relação a maior dificuldade ED aponta que "é apontar os erros, os problemas que estão ocorrendo e não ter uma resposta, não poder resolver. Também tenho dificuldade com a falta de pessoal, quando há falta, preciso cobrir esse meu subordinado." O entrevistado conta que também sofre com a precariedade de alguns materiais e equipamentos necessários para a execução de seu trabalho e da sua equipe.

\subsection{Relacionamento com subordinados}




\section{Revista Cadernos de Economia}

Universidade Comunitária da Região de Chapecó - Unochapecó

Não é de hoje que os relacionamentos são essenciais na vida das pessoas, não apenas na social, mas também na profissional e eles por si só, detém um grande poder. Revelando a importância da relação do líder com o seu liderado, é sabido que o relacionamento deles precisa ser uma via de mão dupla, e que essa relação quando dada de maneira profissional e sadia, gera muitos benefícios para ambos os lados. O líder forma uma equipe mais qualificada, desenvolve o lado pessoal dos seus subordinados e também a equipe, conseguindo assim melhores resultados. Já para o liderado, ter o apoio do seu líder pode deixá-lo mais confortável e motivado para a execução do trabalho, fazendo-o com que adquira para si novas técnicas e habilidades e olhando para o futuro com grandes expectativas.

Com o propósito de descobrir como é a relação líder versus subordinado e se essa poderia ser um dilema a ser enfrentado por esses jovens gestores no seu ambiente de trabalho, os entrevistados responderam a essa questão com muita facilidade e firmeza. A resposta de todos os líderes questionados sobre como seria a sua relação com seus subordinados, foi a mesma: um relacionamento muito bom, tranquilo.

Por unanimidade, isso revela que a questão do relacionamento, não é um dos problemas enfrentados por eles, conforme afirma EA:

\footnotetext{
"nossa relação é bem aberta, bem estreita. A gente tem que ser um líder, e o líder vai à frente. A forma com que eu trabalho é muito confortável para ambos os lados. De uma forma geral, nossa relação é muito boa” (EA).
}

Para ED seu "relacionamento é muito bom, muito bom mesmo, não tenho problemas com ninguém. Às vezes a gente tem que falar, precisa cobrar um pouco, mas no geral não tenho problemas". Contudo, três dos entrevistados fazem um relato motivador e assim como os demais líderes entrevistados, mesmo em meio a problemas que enfrentam, eles se mostram muito satisfeitos com suas posições: "acho que isso é a parte mais gratificante, trabalhar com pessoas" (EB). EC argumenta: "não acho que o fato de eu ser jovem impacta na minha liderança. Não me vejo fazendo outra coisa" e, para EE, "o líder tem que ser um influenciador, ele não pode ser aquele que acusa, aquele que diz vai e faz, mas ele tem que ir lá e mostrar como se faz e todo mundo vai atrás". 


\section{Revista Cadernos de Economia}

Universidade Comunitária da Região de Chapecó - Unochapecó

Para Bunn e Fumagalli (2016, p. 135), “a liderança não se trata apenas de um cargo, um emprego, e sim de qualidades e atitudes que façam com que as pessoas se destaquem e ganhem, assim, admiradores". Entender o papel de cada um nessa relação é fundamental. Esta relação é de interdependência e deve ser construída e mantida de maneira coesa, madura e respeito mútuo, para que todos participem e alcancem os resultados desejados.

\section{CONSIDERAÇÕES FINAIS}

Conforme exposto na introdução do trabalho, o presente estudo buscou compreender alguns aspectos relacionados ao mercado de trabalho, a juventude e a liderança. Embora existam diversas pesquisas e estudos realizados, ou seja, muitos materiais disponíveis que apresentam uma abordagem sobre liderança, esses se limitam quando incluído o tema juventude. Analisando os estudos, apesar de que, segundo especialistas, o número de jovens inseridos no mercado de trabalho tem crescido muito nos últimos anos, praticamente não foram encontrados materiais que apresentam os jovens como liderança e os dilemas que eles enfrentam na sua gestão. Assim, o presente estudo visa diminuir essa lacuna existente e contribuir para o público interessado, seja ele: organização ou jovens que desempenhem função de liderança.

De acordo com a revisão da literatura da pesquisa, as características de liderança em sua grande maioria, são desenvolvidas ao longo a vida, através de experiências. As pessoas nascem com algumas características que podem auxiliá-las no processo de liderança, porém, serão um suporte para as experiências vividas. Após a análise dos dados, podemos concluir que ao caracterizarmos o ingresso no mercado de trabalho desses líderes investigados, mais da metade deles ingressaram no mercado de trabalho muito jovens, com 15 anos sendo a média de idade e motivos distintos. Além disso, foi possível perceber que o primeiro contato com trabalho dos entrevistados se deu de maneira informal, ou seja, sem o registro na carteira de trabalho, o que leva-nos a interpretar que os mesmos já vivenciaram diversas situações em ambientes profissionais, sendo eles favoráveis ou não, contribuindo para a formação e amadurecimento desses jovens. 


\section{Revista Cadernos de Economia}

Universidade Comunitária da Região de Chapecó - Unochapecó

O segundo momento busca compreender a trajetória profissional dos gestores e três dos cinco entrevistados são considerados pelo autor experientes profissionalmente, passando por alguns cargos em pelo menos três outras empresas anteriores a atual. Com isso, conclui-se que os entrevistados apresentam uma experiência considerável no mercado de trabalho, sendo aproximadamente 8 anos em média a experiência do grupo, o que revela algum subsídio para hoje executarem um cargo de liderança. Sobre o histórico na atual empresa, destacamos que a metade dos entrevistados já eram há algum tempo funcionários da empresa e que receberam promoção por se destacarem em seus cargos, o que de certa forma, é um fator facilitador, pois os mesmos já possuem a confiança e conhecem processos e condutas da organização. O restante do grupo ingressou na atual empresa sendo gestores e como consequência disso destaca-se as experiências anteriores como líderes.

Quanto ao relacionamento dos líderes com seus liderados, foi possível analisar que apesar de jovens, de forma unânime, eles relataram não possuir uma relação difícil e sim uma relação aberta, de respeito mútuo, totalmente favorável para que o ambiente seja saudável e o serviço executado da melhor maneira possível.

Através da análise de dados, percebe-se que dentre as características pessoais e/ou profissionais dos entrevistados, a responsabilidade é a sua principal característica positiva, e, como defeito, aproximadamente metade do grupo de entrevistados, relatou ser a falta de paciência um dos pontos negativos, enquanto a outra parte salientou ser a falta de confiança no trabalho dos outros uma característica a ser melhorada por eles.

Ainda foi possível analisar como sendo parte do objetivo proposto da pesquisa, as vantagens e as desvantagens ou dificuldades enfrentadas pelos jovens na liderança. A maioria deles, de maneira surpreendente relatou que a grande vantagem de liderar atualmente, é o fato de poder intervir positivamente na vida das pessoas, fazer a diferença, contribuindo para o desenvolvimento pessoal e profissional delas. Ainda destaca-se que parte do grupo citou o prazer por exercer a função como uma vantagem e também a autonomia foi lembrada por eles.

Já como desvantagens e/ou dificuldades, percebe-se que o fato da liderança exercer muitas responsabilidades, as cobranças e pressões geram certo desconforto aos jovens gestores e o ato de precisarem manter certa formalidade com seus subordinados, 


\section{Revista Cadernos de Economia}

Universidade Comunitária da Região de Chapecó - Unochapecó

não podendo construir muita amizade e intimidade por acreditarem que não seja benéfico ao profissionalismo.

Com isso, conforme o objetivo geral da pesquisa, a saber: investigar os dilemas pessoais e profissionais enfrentados pelos jovens gestores frente a sua equipe de subordinado(s) é possível concluir que o principal dilema enfrentado por eles são as grandes quantidades de responsabilidades que são atribuídas a eles nas suas respectivas atividades, a pressão e a cobrança que são exigidas em um cargo de liderança e esse dilema aponta que as características dos gestores não estão intimamente ligadas ao problema que enfrentam, uma vez que a grande maioria dos entrevistados destacou como principal característica justamente a responsabilidade e o compromisso. $\mathrm{O}$ fato de não poder criar muita intimidade com seus funcionários também reproduz um impasse a eles, uma vez que o jovem, considerado nessa pesquisa, geralmente, não é adepto à formalidade.

Como limitações ao trabalho, pode-se observar a dificuldade na acessibilidade ao objeto de pesquisa, principalmente quando, por opção do autor, se buscou o público feminino, fazendo com que não se equiparasse a questão do sexo dos entrevistados, o que poderia trazer um panorama maior ao objetivo. Assim, é oportuno ressaltar, ainda, a importância de serem realizados mais pesquisas com o tema de liderança jovem, uma vez que existem muitas características no objeto que podem ser fatores diferenciais em seus resultados, como as que foram citadas anteriormente, o sexo do líder e o cargo de liderança que ele ocupa. Também como sugestão, repetir a presente pesquisa, ampliando a sua metodologia, realizando a coleta de dados através da observação e entrevistas com membros da equipe liderada por jovens.

\section{REFERÊNCIAS}

AMARAL, Renata C. G.; OLIVEIRA, Lúcia B. Os Desafios da Primeira Gestão: Uma Pesquisa com Jovens Gestores. RAC, Rio de Janeiro, v. 21, n. 3, art. 5, pp. 373-392, Maio/Jun. 2017

BENDASSOLLI, Pedro. Público, privado e o indivíduo no novo capitalismo. Tempo Social; Rev. Sociol. USP, S. Paulo, 12(2): 203-236, novembro de 2000. BERGAMINI, Cecília Whitaker. Liderando: Administração do sentido. 2. Ed. São Paulo: Atlas, 2009. 162 p. 


\section{Revista Cadernos de Economia}

Universidade Comunitária da Região de Chapecó - Unochapecó

BUNN, Fernanda; FUMAGALLI, Luis A. W. A importância do líder na organização: influenciando pessoas para o atingimento dos resultados. Revista FAE, Curitiba, v. 19, n. 2 , p. 132 -147, jul./dez, 2016.

CHOPRA, Deepack. A alma da liderança. HSM Management, ano 6, $\mathrm{n}^{\mathbf{0}}$ 33, jul./ago. 2002.

CRESWELL, John W. Projeto de pesquisa: métodos qualitativo, quantitativo e misto. 2. Ed. Porto Alegre: Artmed, 2007. 248 p. Disponível em:

$<$ https://edisciplinas.usp.br/pluginfile.php/696271/mod_resource/content/1/Creswell.pdf $>$. Acesso em: 19 out. 2018.

LACOMBE, Francisco J. M. Dicionário de Administração. São Paulo: Saraiva, 2004. 358p.

MARCONI, M. de Andrade; LAKATOS, E. Maria. Técnicas de pesquisa. 5. ed. São Paulo: Atlas, 2002. Disponível em: <https://pt.scribd.com/doc/237629448/tecnicas-depesquisa-marconi-lakatos-pdf $>$. Acesso em: 19 out. 2018. 282p.

MORAES, Roque. Análise de conteúdo. Revista Educação, Porto Alegre, v. 22, n. 37 , p. 7-32, 1999. Disponível em:

<http://cliente.argo.com.br/ mgos/analise_de_conteudo_moraes.html>. Acesso em: 19 out. 2018.

MORAES, Jhony P.; OLIVEIRA, Sidinei R. Inserção Profissional: Uma análise bibliométrica dos estudos brasileiros em bases de dados científicas. Perspectivas em Gestão \& Conhecimento, João Pessoa, v. 9, n. 3, p. 81-101, set./dez. 2019.

MORAIS, Frederico, L. O desafio das lideranças: assegurar a produtividade com pessoas de diferentes gerações. In: ReCaPe Revista de Carreiras e Pessoas São Paulo.

Volume VI - Número 02 - Mai/Jun/Jul/Ago 2016

NEWSTROM, JOHN W. Comportamento organizacional: O comportamento

humano no trabalho. São Paulo: McGraw-Hill, 2008. 508 p.

OLIVEIRA, Marco A. Comportamento organizacional para a gestão de pessoas:

Como agem as empresas e seus gestores. São Paulo: Saraiva, 2010. 422 p.

PESSOTTI, Patrícia. Papel do líder na organização. 2012. Disponível em:

$<$ http://www.rh.com.br/Portal/Lideranca/Artigo/7964/o-papel-do-lider-na-

organizacao.html\#>. Acesso em: 17 out. 2018.

ROBBINS, S. P. Comportamento organizacional. 14. Ed. São Paulo: Pearson Prentice Hall, 2010. 633 p.

ROCHA, Sonia. A inserção dos jovens no mercado de trabalho. Cad. CRH, Salvador, v. 21, n. 54, p. 533-550, Dez. 2008.

ULRICH, Dave; SMALLWOOD, Norm; SWEETMAN, Kate. O código da liderança: Cinco regras para fazer a diferença. Rio de Janeiro: BestSeller, 2009. 191p. 